\title{
Effects of Organisational Characteristics on Contractors' Construction Cash Flow Forecasting Capabilities
}

\author{
Muhammad Abdullahi ${ }^{1}$, Yahaya Makarfi Ibrahim², Ahmed Doko Ibrahim ${ }^{3}$, and Hasssan Adaviriku Ahmadu ${ }^{4}$ \\ ${ }^{1}$ Lecturer, Department of Quantity Surveying, Ahmadu Bello University, Zaria, Nigeria, E-mail: \\ abdullahimohammad@abu.edu.ng (corresponding author). \\ ${ }^{2}$ Associate Professor, Department of Quantity Surveying, Ahmadu Bello University, Zaria, Nigeria. \\ ${ }^{3}$ Professor, Department of Quantity Surveying, Ahmadu Bello University, Zaria, Nigeria. \\ ${ }^{4} \mathrm{PhD}$ student, Department of Quantity Surveying, Ahmadu Bello University, Zaria, Nigeria.
}

Project Management

Received November 10, 2016; received revision December 28, 2016; accepted January 9, 2017

Available online January 23, 2017

\begin{abstract}
Inadequate cash resources resulting from poor cash flows have been among the fundamental causes of construction project failures. Despite the panoply of cash flow forecasting (CFF) tools, the cash flow performance of many construction firms have been reported to be poor due weak Cash flow forecasting (CFF) process capabilities influenced by a couple of organisational characteristics. Although these organisational characteristics have been reported to significantly influence firms' CFF process capabilities, the underlying mechanisms of how these organisational features and characteristics exhibit their specific influences on the cash flow forecasting capabilities of construction firms still remains underexplored. Therefore, this study aims at empirically exploring the influence of some organisation characteristics on the CFF process capabilities of construction firms. Best practices in CFF identified from the Royal Institute of Chartered Surveyors (RICS) Cash Flow Forecasting (CFF) guide were used to develop an assessment criteria used to assess the CFF capabilities of construction firms. The assessment was conducted through a questionnaire survey involving contracting organisations involved in both building and civil engineering works in Nigeria. The key best practices in CFF were ranked based on arithmetic mean value scores and averages were also determined for each of the four CFF components assessed (Knowledge and understanding CFF concepts and principles, Practical application, Practical considerations, and other Managerial issues). Hierarchical regression analysis was then used to examine the relationships between contractors" CFF process capabilities and some organisational characteristics. Results of the study reveals that organisational characteristics are strongly associated to firms' abilities to prudently manage cash flows. The results of this study could serve as a basis for the strategic planning and improvement of Cash Flow Forecasting process by contractors in Nigeria.
\end{abstract}

Keywords: Cash flow forecasting, hierarchical regression, process capabilities, RICS.

\section{Introduction}

The effective management of cash flows is one of the fundamental priorities of all construction firms working with numerous uncertainties that directly influence the project objectives of cost, time and quality. Cash flow management according to $\mathrm{Cu}$, Hastak and Halpin (2010) involves the forecasting, planning, monitoring and controlling of cash receipts and payments. To ensure that construction cash flows are effectively planned and managed, construction organisations practice Cash flow Management at two basic levels; project and organisational levels. While at the project level, the cash flows of individual projects are analysed separately, the management of Cash flows at the strategic management level, involves the development of policy and framework for managing the entire organization's cash flow including non-construction projects and other investments. However, due to the specific characteristics and behavior of cash flows at each of these levels, various tools have been developed to assist in the preparation of accurate and reliable cash flow forecast. Using either the 'Deterministic' or 'Stochastic' approaches, studies have developed several cash flow forecasting tools ranging from statistical (Kenley and Wilson, 1986, 199); mathematical (Miskawi, 1989; Khosrowshahi, 1991; Kaka and Price, 1991, 1993; Evans and Kaka, 1998); to the application of artificial intelligence (Odeyinka et al., 2013; Bousssabaine and Kaka, 1998; Boussabaine et al., 1999; Bousssabaine and Elhag, 1999). More recently, the concept Building Information Modeling (BIM) has been used to develop BIM-based cash flow analysis models (Kim and Grobler, 2013; Lu et al., 2015). However, the choice and success of implementing any of these tools hugely relies on 
firm's Cash flow forecasting (CFF) process capabilities (Abdulrazaq et al., 2012; Abdullahi et al., 2014).

The Cash Flow Forecasting (CFF) process capabilities of firms have been reported to be influenced by organisational profiles and characteristics. Organisational characteristics such as firm size, organisational structure, experience in construction business, nature of works carried out; firms' most widely adopted procurement method in project delivery are notable organisational characteristic reported to have strong links to the process capabilities of construction firms. Odeyinka, Kaka, and Morledge (2003) examined the cash flow management approaches employed by UK construction contractors and found firm size to have direct implications on the approach used by the various categories of firms. Abdulrazaq, Ibrahim, and Ibrahim (2012) and Abdulrazaq (2015) observed a disparity of practices along three categories of large contractors in Nigeria (indigenous, expatriates who run indigenous businesses and multi-national corporations who run their businesses within and outside the country) and attributed that to the differences in their organisational policies and characteristics. Large construction firms that have strong capacity and technical competence of handling large and complex projects of huge contract sums are likely to have well-developed and robust cash flow management system than small and medium firms whose capacities are still developing. Odeyinka (2014) and Abdullahi et al. (2014) in their respective studies both posited an association between the size of firms and their cash flow management practices.

On the other hand, previous studies have reported a strong link and association between firms' level of experience and nature of works executed to their overall performance. The vast experiences in various kinds of construction works accumulated by contractors is said to have immense contribution to their respective performance and plays significant role in their overall success in the construction business (Kenley and Wilson, 1986). Similarly, poor and ineffective CFM practices have been attributed to the several business failure recorded in the construction industry (Kaka, 1999) with most of the affected firms being the small and medium enterprises (SMEs). This is largely due to their lack of experience in construction business and also their inability to diversify their business goals at time of difficulties. Therefore, because these insolvencies strike along some particular category of firm whose experiences in construction is low, it then clearly suggests that organisational features in terms of the extent of experience in construction business and also the nature of works carried out by the firms could affect the capabilities of these firms in their approach to cash flow management.

Similarly, the CFF process capabilities of construction firms is influenced by the procurement routes and contract conditions used in projects executed by the firms. Kaka and Khosrowshahi (1996) established that project cash flows vary along different procurement routes such as the design-bid-build, design and build, management contracting and even other conventional procurement systems such as public private partnership arrangements. This clearly suggests a linkage between the various procurement methods employed in executing projects and firms' capabilities of managing cash flows. Kaka and Lowe (1996) confirmed that differently procured projects with different sizes and based on different contract condition produce different cash flow patterns. In addition, results of series of simulation tests conducted to evaluate the extent of variation in the cash flow, given different contract conditions revealed that, variation in procurement routes has a significant effect on contract cash flows.

While all these organisational characteristics have been reported to significantly influence several organisational issues and dimensions such as people, management and technology, the underlying mechanisms of how these organisational features and characteristics of contractors exhibit their specific influences on the cash flow forecasting capabilities of these contractors still remains underexplored. Also, the nature of the relationship between these organisational characteristics and firms' CFF process capabilities is yet to be uncovered. Hence, this study aims at empirically identifying how contractors' organisational characteristics are associated with their CFF process capabilities. Findings from this research provide policy makers in construction firms with adequate explanations of how and extent to which various organisational characteristics influence their CFF process capabilities. The following sections of this paper present a brief review of previous research on cash flow forecasting, best practices in CFF, the research method adopted, and subsequently the results and conclusions of the research.

\section{Literature Review}

\subsection{Cash Flow Management Approaches}

The management of Construction Project Cash Flows (CPCFs) has been a fundamental concern to construction project managers whose goals are to deliver projects on time, within budget and to the required quality standards. Based on that, the modelling of construction cash flows has received significant attention in the last decades (Bromilow and Henderson, 1977; Hudson, 1978; Singh and Woon, 1984; Kenley and Wilson, 1986; Miskawi, 1989; Khosrowshahi, 1991; Evans and Kaka, 1998; Skitmore, 1992). This can be directly attributed to the utmost need of ensuring stable financial position at all times throughout the lifecycle of the project. Accurate cash flow statements provide contractors with information regarding the amount of capital required, the amount of interest needed to support overdrafts and the evaluation of different tendering strategies (Harris and McCaffer, 2005). Also, as construction progresses, accurate forecast could serve as a cost control tool (Odeyinka and Lowe, 2001). On the other hand, poor cash flow management practices affect projects negatively, that could lead to unnecessary delays, cost and time overruns and in some cases project abandonment and company failure (Kaka and Price, 1991). The construction industry has been reported to have recorded the highest number of insolvencies than any other sector of the economy. For example, $17.5 \%$ cases of bankruptcies were reported in the UK alone in 
1989 (Kaka, 1999). These insolvencies were mostly attributed to poor financial management practices resulting from the inadequate attention given to cash flow issues at project and corporate levels. Therefore, as a way of tackling these problems, researchers have employed various approaches (deterministic and stochastic) to develop tools that facilitate the effective and efficient management of construction cash flows in the last decades.

Deterministic approaches have been employed to forecast, plan, monitor and control construction cash flows ranging from traditional approaches to short-cut techniques and the use of artificial intelligence systems. The traditional method of managing cash flow according to Harris and McCaffer (2005) requires the calculation of actual quantities for each time interval according to progress schedules and then multiplying them by the estimated unit costs. The forecast prepared is then subsequently monitored and managed to ensure smooth running of the project. This approach is known as the cost-schedule integration method and has been reported to be one of the most accurate techniques for managing cash flows (Chen, O'Brien, and Herbsman, 2005). However, because of the tedious and time consuming nature of this approach, the need for faster and simpler cash flow management (CFM) techniques became necessary and therefore alternative short-cut modelling techniques ranging from mathematical, statistical to the application of artificial intelligence were employed by researchers.

Several research efforts have been invested in developing CFAM) models based on short-cut approaches that hugely rely on historic data. Early studies have concentrated in developing standard S-curves that could predict construction cash flows at the various stages of projects (Bromilow and Henderson, 1977; Hudson, 1978; Singh and Woon, 1984; Kenley and Wilson, 1986; Miskawi, 1989; Khosrowshahi, 1991; Evans and Kaka, 1998; Skitmore, 1992). This approach models cash flow using cost flow, value flow and net cash flow using mathematical and statistical tools such as the polynomials, logit transformation model, and multiple regressions were used to develop these CFM tools. Although the shortcut techniques were adjudged to be faster and cheaper than the S-curves, studies have observed several weaknesses associated to them. Kaka and Price $(1991,1999)$ reported that the net cash flow is difficult to model and the value curves are affected by tender unbalancing. Also, Kenley and Wilson (1986) found estimates produced by the nomothetic models to varying widely from actual data. However, these methods were later on improved with the use of computer spread sheets and Artificial Intelligence (AI) methods such as fuzzy logic and Artificial Neural Networks (ANN) (Odeyinka et al., 2013; Bousssabaine and Kaka, 1998; Boussabaine et al., 1999; Bousssabaine and Elhag, 1999).

To address some of the weaknesses in the deterministic models, stochastic methods have been employed to cash flow modelling. The stochastic methods basically model risks and uncertainties likely to impact on cash flows. Taking into account the vagueness and ambiguities inherent in the estimation of projects' cash flows, Boussabaine and Elhag (1998); Chen et al. (2002) and Kishore et al. (2011) applied fuzzy set theory to develop cash flow analysis models that take into account the uncertain behaviour of construction cash flows. Zayed and Liu (2014) combined Artificial Hierarchy Process (AHP) and simulation techniques to model the uncertainty factors impacting on cash flows in their probabilistic cash flow model. Cheng and Roy (2011) applied proactive approach to monitor cash flow management using AI hybrid system that fused fuzzy logic (FL), weighted support vector machines (weighted SVMs) and fast messy genetic algorithms (fmGA). Kaka and Lewis (2003) developed a dynamic cash-flow forecasting system that uses simulation to generate projects and allows planning the cash flows at project and company levels. Although, these panoply of approaches tremendously improved cash flow management process, they were criticized of being manually driven and found to be tedious and time consuming (Odeyinka et al., 2013). This led to the development of automated processes that focus on accuracy, speed and efficiency (Kaka, 1996; Kim and Grobler, 2013; Lui et al., 2016).

Studies have explored the automation of construction cash flow analysis and management process and have developed software applications that eliminate the manual exercises attributed to previous methods (Kim and Grobler, 2013; Lu et al., 2016). For example, spreadsheets solutions, computerized cost-schedule integration techniques are typical example of automated systems developed by researchers. Khosrowshahi (2000) reported the development of the Advanced S-Curve (TASC); a software that aids cash flow forecasting. Other CFM software applications developed include FINCASH developed in Australia, and Cybercube developed in the UK (Odeyinka, 2003). More recently, Building Information Modeling (BIM) based cash flow analysis (CFA) models have been developed by researchers. Kim and Grobler (2013) developed a BIM-based CFA prototype system that extracts quantity, schedule and cost information from BIM objects, schedule and cost databases respectively to perform cash flow analysis. Although the prototype system was based on IFCXML format, it lacks the ability to adequately interoperate with other similar and related applications. Similarly, Lu et al. (2016) developed an add-in to a 5D BIM that extended the cost management functions of a $5 \mathrm{D}$ model to cash flow analysis and financing. The add-on also lacks seamless data exchange capabilities and can only interact with the parent application.

\subsection{Best Practices in Cash Flow Forecasting Process}

The Royal Institute of Chartered Surveyors' CFF Practice guidance note (2012) provides best practice guidance on cash flow forecasting to project and cost managers in all world regions. The document summarises what cash flow forecasting is, how to produce a useful forecast and how to use the forecast to assess progress on site, as well as several other issues. The main aim of the guide is to assist both employers and contractors to analyse actual expenditure against forecast expenditure in a uniform approach and to ensure that consistent practice is delivered in a professional manner that is in line with the globally recognised guidance. Guidance is given based on 
the main forms of contract and main procurement routes, under the following headings which corresponds to RICS Assessment of Professional Competence (APC) methodology:

- General principles (Level 1: Knowing): This is the first process area of a successful CFF process and according to the RICS CFF guide (2012), guidance is given in this section in respect of; what purposes cash flow forecasts are used for; their usefulness in terms of running a business and predicting business failure; the various contractual mechanisms for dealing with cash flows; the relevant legislative items and the formulas or 'curves' used to predict the cash flow for construction project. RICS CFF guide (2012) as shown on Table 1 enumerates the various concepts and principles that describe best practices under 'Knowing'.
- Practical application (Level 2: Doing): This directly involves the practical application of the generally established principles and concepts that ensure successful management of construction project cash flows. A total of twenty six (26) best practices that define the best way of practicing cash flow forecasting are listed in Table 1.

- Practical considerations (Level 3: Doing/ Advising): This looks at the practical considerations that have to be made when producing and analysing cash flow forecasts. A chartered surveyor should consider the following when advising on the uses of a cash flow forecast and, in particular, when using the cash flow forecast to monitor progress on site or when assessing claims.

Table 1 presents the list of key best practices as outlined by RICS CFF Practice guidance note (2012).

Table 1. RICS Key Best Practices (KPBs) in cash flow forecasting

\begin{tabular}{|c|c|}
\hline \multicolumn{2}{|c|}{ General Principles } \\
\hline \multirow{6}{*}{\multicolumn{2}{|c|}{$\begin{array}{c}\text { Understanding of the uses and purposes of CFF } \\
\text { Awareness of the influence of different valuation methods on CFF } \\
\text { Knowledge of influence of cash flow on business failure } \\
\text { Understanding of legislative requirements on CFF } \\
\text { Knowledge of CFF curves and formulae } \\
\text { Knowledge of advance cash flow forecasting tools }\end{array}$}} \\
\hline & \\
\hline & \\
\hline & \\
\hline & \\
\hline & \\
\hline \multicolumn{2}{|c|}{ Practical Application } \\
\hline Deciding appropriate approach & Providing risk allowance \\
\hline Taking brief from employer & Providing risk allowance for provisional sums \\
\hline Preparing program of works & Adding cost centres \\
\hline Ascertaining basis of forecast & Adjusting materials on and off site \\
\hline Adjusting forecast for cyclical events & Seeking specialist advice for CFF of specialist works \\
\hline Adjusting schedule for holiday & Adjusting forecast to reflect progress on site \\
\hline \multirow{2}{*}{$\begin{array}{l}\text { Incorporating retention percentage } \\
\text { Adjusting cash flow forecast to extend to rectification } \\
\text { period }\end{array}$} & Managing the effects of delays on CF \\
\hline & Use of spread sheet for CFF \\
\hline Analysing delays for certification period & Using value approach to predict cash flows \\
\hline Including payment delays in forecast & Using cost approach to predict cash flow \\
\hline \multirow{3}{*}{$\begin{array}{c}\text { Considering sectional completion/partial possession } \\
\text { Adjusting currency difference } \\
\text { Providing risk allowance for variation }\end{array}$} & Using detailed approach to predict cash flows \\
\hline & Using short-cut approach to predict cash flows \\
\hline & Using Artificial intelligence to predict cash flows \\
\hline Practical Considerations & Management Issues \\
\hline \multirow{8}{*}{$\begin{array}{c}\text { Representing forecast in graphical form } \\
\text { Analysing reasons for variances } \\
\text { Discussing variances with the employer } \\
\text { Analysing actual payment against forecast } \\
\text { Checklisting CF risks } \\
\text { Forecasting the effects of claim on CFF } \\
\text { Considering the effects of re-sequencing and work } \\
\text { acceleration }\end{array}$} & Management's commitment \\
\hline & Highly trained staff \\
\hline & Organisational Policy \\
\hline & Evaluation and review of CFF process \\
\hline & Verify whether forecasts are based on Procedures \\
\hline & \\
\hline & \\
\hline & \\
\hline $\begin{array}{l}\text { Aavising on the errects or local taxation } \\
\text { Considering effects of alternative procurement routes }\end{array}$ & \\
\hline Ensuring data richness and information accuracy & \\
\hline
\end{tabular}

\section{Research Methods}

To empirically test the influence of some selected organisational characteristics on the firms' $\mathrm{CFF}$ capabilities, a combination of research methods was adopted. Firstly, the review of relevant literature was carried out basically to identify the best practices in cash flow forecasting and the various organisational characteristics of construction firms. The best practices identified were used in developing the assessment criteria 
for evaluating firms' capabilities. The literature review identified a list of CFF best practices developed by the RICS as best practices guideline for CFF which were used in developing a questionnaire used for data collection. The second stage involved a questionnaire survey. The questionnaire survey was carried out to assess the CFF capabilities of the different group of contractors selected for the study, particularly on the extent to which the CFF best practices are applied in their organisations. The survey succinctly captured the organisational characteristics purported to be associated to the firms' cash flow forecasting process capabilities. The entire research process is depicted in Fig. 1.
The complete questionnaire comprised three sections: questions about respondents' background; questions about some key relevant organisational characteristics; and questions on cash flow forecasting practices. Five (5) major organisational characteristics identified in literature were considered as the independent variables and properly captured in section B of the questionnaire. The assessment of best practices in CFF used in determining the strengths and weaknesses of construction firms was done based on the various types of firms involved in the questionnaire survey.

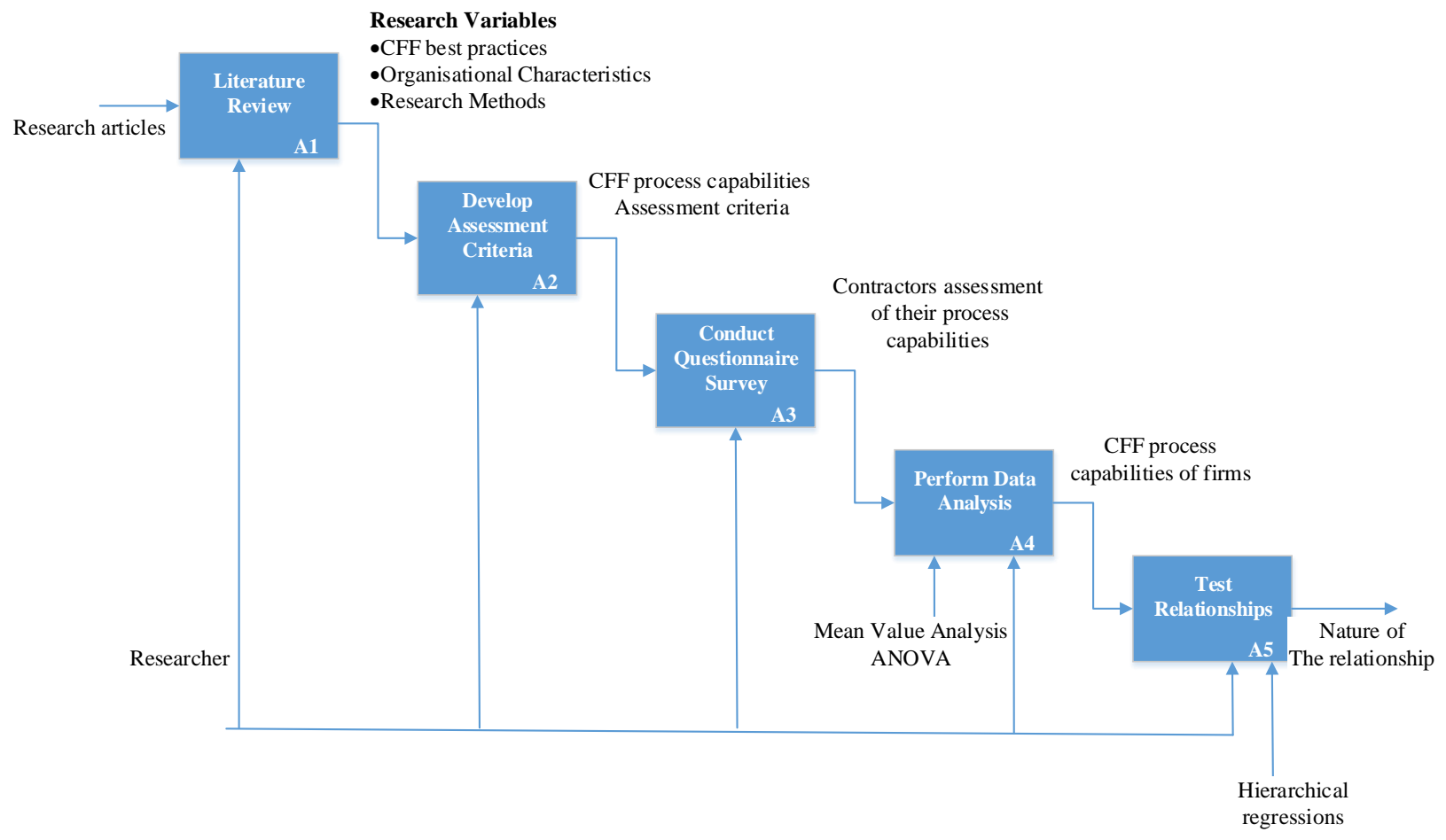

Fig. 1. The research process

\subsection{Study Sample and Data Collection}

The questionnaire was administered on a sample comprised of duly registered construction firms of various sizes who remit their taxes with the Federal Inland Revenue Service of Nigeria (FIRS); a statutory authority mandated for the collection of taxes in Nigeria. According to the FIRS (2016), there are Ten thousand, two hundred and thirteen $(10,213)$ active contractors across the country, and using Cochran (1977) table and correction formula, a sample size of 370 construction firms was computed and considered as the study sample. Purposive sampling method was employed to select the firms involved in the survey. The sample selection was based on the assumption that all the firms considered in the sample frame consider CFF very important and engage qualified personnel to perform the duty. The purposive sampling method was adopted to ensure that only firms that practice cash flow forecasting are involved in the survey. Hence, only firms that are capable of providing the required information needed in the study were contacted. This is based on the fact that not all construction firms practice CFF formally as recommended in literature (Abdulrazaq et al., 2012).

The survey targeted construction professionals with vast experience in construction finance. Respondents were asked to rate the extent of usage/application of the key best practices in CFF using a Likert scale of $0-5$ where; 0 indicates "no usage/application", 1 "little usage/application", 2 "some usage/application", 3 "moderate level of usage/application", 4 "High level of usage/application" and 5 "Highest level of usage/application". A total number of 86 usable responses representing $23 \%$ response rate were used for analysis. The key best practices were ranked based on arithmetic mean value scores and averages were also determined for each of the four components assessed (Knowledge and understanding CFF concepts and principles, Practical application, Practical considerations, and other Managerial issues). Hierarchical regressions were subsequently employed to test the influence of the 
organisational characteristics on contractors' CFF capabilities.

\section{Results and Discussion}

Based on the review of literature carried out, an assessment criterion was developed and categorised into four distinct components which are indicators of best practices in CFF. The four CFF process areas/components are:

- The understanding and knowledge of CFF principles and process (knowing).

- Practical application of the concepts and principles into live projects (doing).

- Practical considerations of the practices (Advising).

- Management related issues.

The first three components were direct extracts from the Royal Institute of Chartered Surveyors (RICS) Professional Guidance Note (2002) while the management related issues were identified from literature (Abdulrazaq et al., 2012). The guidance note provides best practices on cash flow forecasting for project and cost managers all over the world and is based on the RICS assessment of professional competence approach. The main purpose of the guide is to ensure that consistent practice is delivered in a professional manner that is in line with internationally recognised guidance. The guide sets a framework for best practice, subject to specific local legislative requirements and local market specifics. Respondents were presented with a long list of The CFF capabilities of the contractors surveyed and were asked to assess CFF process capabilities of their organisations based on these criteria. Each criterion (process area/component) is made up of sub-criteria which provide more details on the requirement of the main criterion (component). The sub-criteria are comprised of the best practices that describe what CFF is, how to produce a good cash flow forecast and then how to use the forecast to assess progress on site and other issues.

Table 2 shows the demographics of the surveyed respondents and construction firms involved in the study.

Most of the respondents as shown on Table 2 were Quantity surveyors (44.2\%) who are mostly saddled with the responsibility of preparing cash flow forecasts. Another $38(22.1 \%)$ were Architects and Structural Engineers while only $10(11.6 \%)$ were Building services engineers. With quantity surveyors, Architects and Engineers dominating the responses, it could be implied that reliable responses would be obtained. The respondents were grouped based on their level of experience in construction and specifically their experiences in dealing with cash flow issues. This could be an indicative of the quality of responses gathered. Most of the respondents are experienced, with $81.4 \%$ having over 5 years of relevant experience in the construction sector. This clearly suggests that they are used to cash flow issues and would give accurate responses in the survey. With regards to the respondents' positions in their organisations, $54 \%$ of them occupy the middle management level, while about $44.2 \%$ of them are part of the top management who take vital and strategic decisions for the organisation and are usually responsible for cash flow forecasting and management issues, hence, likely to provide the required and reliable information.

Similarly, as shown on Table 3 , majority of the firms are highly experienced with long years of work experience in the industry. About $60 \%$ of them have been into construction business for over 10 years gaining relevant experience in the construction sector. This wide range of experience can be very valuable in assessing the effects of organisational characteristics on the firms' project cash flow forecasting practices.

Table 3 also shows the various proportions of the services offered by the organisations surveyed; their various sizes based on their annual turnovers; most adopted procurement methods; and the organisational structure in place. A total of $69.8 \%$ of the contractors are purely into building constructions, $22.1 \%$ are involved in civil engineering works while only $8.1 \%$ are into both building and civil engineering contracts. This clearly shows that the sample is made up of both building and civil engineering contractors which is usually capital intensive involving huge capital outlay and longer contract durations.

\subsection{Cash Flow Forecasting Process Capabilities of Nigeria Contractors}

The average CFF process capabilities of Nigerian construction firms are shown on Tables 4 and 5.

\subsubsection{Large firms' CFF Process Capability}

The large firms have an overall average group mean of 3.48 implying that the practice is at a high level of application with high capability. Firms under this group have high understanding and knowledge (knowing) of the basic concepts and principles of CFF (overall mean=3.95); moderate level of practical application (Doing) of the concepts and principles (Overall mean $=3.46$ ), a low level of applying those practical considerations (Doing /Advising) into their forecasting process (Overall mean=2.89). An overall mean value of $\mathbf{3 . 6 1}$ for management related issues also depicts a high level of application of managerial practices. Therefore, the results clearly shows that large firms have higher capabilities in the areas of "Knowing" and "Management of CFF process" while moderate and weak capabilities in the areas of Practical application (Doing) and Practical considerations (Doing/Advising) respectively.

\subsubsection{Medium firms' CFF Process Capability}

The medium firms have an overall group average of $\mathbf{2 . 5 8}$ lower than that of the large firms. This means that the medium sized firms are also at a low level of CFF practice with low capability. Firms under this group have their relative strengths in the areas of "Knowing and Doing" while weak in the "Advisory and Management" aspect of the process. However, because the rating scale ranges from 0 to 5, this means than the contractors under this group still have substantial opportunity to improve their capabilities, especially in the areas of Doing/advising (Overall mean=1.58) and managing 
(Overall mean=1.52) where capabilities are extremely low.

\subsubsection{Small firms' CFF Process Capability}

The small firms with overall mean value of $\mathbf{1 . 8 2}$ have a very low CFF Capabilities. They have low capabilities in the areas of Knowing and Doing; very low capabilities in Doing/Advising; and completely incapable in the management component of the process. The small firms do not apply any of the management best practices in their CFF process. This could possibly be the simple reason for the poor accuracy in their cash flow forecasts. A good management setting usually have planning, monitoring and controlling systems which collectively ensure effectiveness and efficiency. Therefore, the small firms need to seriously work towards achieving tremendous improvements in their management capabilities by applying those management related key practices that will improve the overall capability of their CFF process.

\subsubsection{Industry CFF Process Capability (Overall):}

The entire industry based on the sample studied having a mean value of $\mathbf{2 . 4 5}$ has low CFF capability. The industry is relatively moderate in the areas of knowing and doing, while very weak in the other two process areas; Doing/advising and management/controlling. High level of improvement is needed in all the components to achieve higher accuracies in cash flow forecasting.

Table 2. Respondents background information

\begin{tabular}{cccc}
\hline Variables & Categories & Frequency & Percent \\
\hline Discipline & Architecture & 19 & 22.1 \\
& Quantity Surveying & 38 & 44.2 \\
& Structural Engineering & 19 & 22.1 \\
& Building Services & 10 & 11.6 \\
\hline Experience & Less than 5 years & 10 & 11.6 \\
& $5-15$ years & 43 & 50.0 \\
& $16-25$ years & 25 & 29.1 \\
& Above 25 years & 8 & 9.3 \\
\hline Position & Top management level & 38 & 44.2 \\
& Middle management level & 47 & 54.7 \\
\end{tabular}

Table 3. Background information of the surveyed organisations

\begin{tabular}{|c|c|c|c|}
\hline Variables & Categories & Frequency & Percent \\
\hline \multirow[t]{3}{*}{ Services Offered } & Building works & 60 & 69.8 \\
\hline & Civil engineering works & 19 & 22.1 \\
\hline & Both & 7 & 8.1 \\
\hline \multirow[t]{5}{*}{ Firm Experience } & Less than 5 years & 13 & 15.1 \\
\hline & 6-10 years & 21 & 24.4 \\
\hline & $11-15$ years & 31 & 36.0 \\
\hline & $16-20$ years & 14 & 16.3 \\
\hline & $21-25$ years & 7 & 8.1 \\
\hline \multirow[t]{3}{*}{ Annual Turnover } & N10-N100M & 35 & 40.7 \\
\hline & N100-N300M & 37 & 43 \\
\hline & Over 300M & 14 & 16.3 \\
\hline \multirow[t]{4}{*}{ Procurement Method often used } & Traditional Method & 56 & 65.1 \\
\hline & Design and Build (DB) & 17 & 19.8 \\
\hline & Management Contracting & 6 & 7 \\
\hline & Construction Management & 7 & 8.1 \\
\hline
\end{tabular}

Table 4. Overall capabilities of the various components of a cash flow forecasting process

\begin{tabular}{cccccccccc}
\hline \multirow{2}{*}{$\begin{array}{c}\text { CFF Process } \\
\text { Areas }\end{array}$} & \multicolumn{2}{c}{ Industry } & \multicolumn{2}{c}{ Large Firms } & \multicolumn{2}{c}{ Medium Firms } & \multicolumn{2}{c}{ Small Firms } \\
\cline { 2 - 9 }$y$ & Mean & SD & Mean & SD & Mean & SD & Mean & SD \\
\hline Knowing & 3.42 & 0.97 & 3.95 & 0.59 & 3.69 & 0.46 & 2.63 & 0.51 \\
Doing & 3.24 & 0.99 & 3.46 & 0.52 & 3.51 & 0.71 & 2.86 & 0.83 \\
Doing/Advising & 1.69 & 1.01 & 2.89 & 0.41 & 1.58 & 0.86 & 1.32 & 0.67 \\
Managing & 1.86 & 1.22 & 3.61 & 0.64 & 1.52 & 0.79 & 0.46 & 0.66 \\
\hline
\end{tabular}


Table 5. Overall cash flow forecasting capabilities of the firms

\begin{tabular}{cccccccc}
\hline & $\begin{array}{c}\text { Large } \\
\text { Firms' } \\
\text { overall } \\
\text { Mean }\end{array}$ & $\begin{array}{c}\text { Standard } \\
\text { Deviation } \\
\text { (SD) }\end{array}$ & $\begin{array}{c}\text { Medium } \\
\text { Firms' } \\
\text { overall } \\
\text { Mean }\end{array}$ & $\begin{array}{c}\text { Standard } \\
\text { Deviation } \\
\text { (SD) }\end{array}$ & $\begin{array}{c}\text { Small } \\
\text { Firms' } \\
\text { overall } \\
\text { Mean }\end{array}$ & $\begin{array}{c}\text { Standard } \\
\text { Deviation } \\
\text { (SD) }\end{array}$ & $\begin{array}{c}\text { Industry } \\
\text { Overall } \\
\text { Mean }\end{array}$ \\
\hline $\begin{array}{c}\text { Cash flow } \\
\text { forecasting } \\
\text { capabilities }\end{array}$ & 3.48 & 1.71 & 2.58 & 1.79 & 1.82 & 1.88 & 2.62 \\
\hline
\end{tabular}

Table 6. ANOVA test results for the mean difference of CFF process areas across the various organisational characteristics

\begin{tabular}{|c|c|c|c|c|c|c|c|c|c|c|}
\hline \multirow{3}{*}{$\begin{array}{c}\text { CFF Process } \\
\text { Areas }\end{array}$} & \multicolumn{10}{|c|}{ ANOVA } \\
\hline & \multicolumn{2}{|c|}{ Size } & \multicolumn{2}{|c|}{ Nature of works } & \multicolumn{2}{|c|}{$\begin{array}{c}\text { Firms } \\
\text { Experience }\end{array}$} & \multicolumn{2}{|c|}{$\begin{array}{c}\text { Procurement } \\
\text { method }\end{array}$} & \multicolumn{2}{|c|}{$\begin{array}{c}\text { Organisational } \\
\text { Structure }\end{array}$} \\
\hline & $\mathrm{F}$ & Sig. & $\mathrm{F}$ & Sig. & $\mathrm{F}$ & Sig. & $\mathrm{F}$ & Sig. & $\mathrm{F}$ & Sig. \\
\hline Knowing & 120.910 & .000 & 2.027 & .038 & 1.421 & .034 & 3.463 & .020 & 4.376 & .016 \\
\hline Doing & 17.465 & .000 & 1.908 & .045 & .321 & .013 & .236 & .001 & .662 & .018 \\
\hline Doing/Advising & 73.934 & .000 & 3.021 & .004 & 2.722 & .035 & 1.379 & .025 & 3.233 & .044 \\
\hline Managing & 238.788 & .000 & 4.273 & .03 & 5.347 & .001 & 3.075 & .032 & 5.452 & .004 \\
\hline
\end{tabular}

\subsection{Testing Relationships: Hierarchical Regression Analysis}

In order to examine the effects of organisational characteristics on the CFF process capabilities of construction firms, hierarchical regression analysis was run in SPSS version 21.The five organisational characteristic considered in this study were selected because the one way ANOVA test results in Table 6 reveals that significant differences exist between the various $\mathrm{CFF}$ process areas and the organisational characteristics considered in this study. Therefore, the hierarchical regressions were performed using both the full sample data combining all the four process areas (Managing, Knowing, Doing, and Advising), and the respective CFF process capability groups as shown in Tables 7.This paper reports only the results generated from the full data on the basis that the overall impact of all the organisational features regressed is more significant when it comes to the strategic management of cash flows.

Hierarchical regression analysis enables the incremental effects of each block of variables to be more clearly observed by controlling for the effects of other factors. It is mostly employed where some predictors have already been established and the effects of new additional predictors are to be tested. In this study, a total of five separate hierarchical regressions were performed, based on the four CFF process areas (Managing, Knowing, Doing, and Advising) taken as the dependent variables. Fig. 2 shows the organisational characteristics mapped to the various CFF process capability dimensions. For each of these regressions, the blocks of independent variables were entered separately. Firm size was first entered to develop Model 1, and then four (4) other organisational characteristics: firms' experience, organisation structure, nature of works, and procurement approach were subsequently entered to develop Model 2 for each of the four (4) CFF process areas. The hierarchical regression results for the individual process areas and the for firm's overall capability are presented in Table 7.

The resulting models ( 1 and 2 ) were considered to be statistically significant with P-values of 0.000 each, which is below the $95 \%$ confidence level considered. This suggests a significant relationship, although not all of the variability in the CFF capabilities of the contractors was explained by the models. Only $63 \%$ and $66 \%$ of the variations were accounted for by the organisational characteristics as indicated in the models. This is not surprising as various organisations exhibit various cultures and behaviours. Therefore, The R2 is considered reasonable due to the diverse nature of the organisations in terms of the kinds of projects they execute, culture and behaviour.

With the results producing a tolerance and variance inflation factors (VIFs) of 1 and a tolerance range of 0.24-0.7 for Model 1; and a VIF range of 1.10-1.26 with a tolerance range of $0.04-0.91$ which are well below the standard cut-off of 0.1 and 10 (Hair et al. 2010), it suggests that the problem of multicolinearity is not substantively influencing the regression results. Model 1 has an $\mathrm{R}^{2}$ value of 0.628 and $\mathrm{F}(1,84)$ of 141.46 and $\mathrm{p}$ value of less than $0.01(0.00)$, the results confirms that firm size is a significant predictor of firms' CFF process. Similarly, for Model $2, \mathrm{R}^{2}=0.66$ and $\mathrm{F}(5,80)=31.12$ and p-value of less than $0.01(0.00)$, the results indicate that combined as a group, 'firm size' together with the other organisational characteristics of 'Firm experience', 'Organisational Finance structure', 'Nature of works carried out and 'Procurement method widely adopted in delivering projects are significant predictors of firms' $\mathrm{CFF}$ process capabilities. This corroborates the findings of Okunlola and Johnson (2013) that unless appropriate procurement routes are selected, project objectives are not likely to be achieved. This is because effective management of several project fundamentals (e.g cash flow) depends on the right choice of procurement method. 
As shown in Table 7 for Model 1, 'firm size explains $62.8 \%$ of the variances in the overall CFF process capability of the firms, while the other four control variables (experience, organisational structure, nature of works, and procurement method) in total could explain $66 \%$ of the variances. Regarding the separate effects of the control variables (organisational characteristics), 'firms experience in construction business' is revealed to have significant negative relationships both $(\beta=-0.06, \quad p<0.01)$. This clearly confirms Abdulrazaq et al. (2012) finding that the large foreign construction firms (in Nigeria) with very high level of experience have more mature and developed cash flow management practices in their various organisations. It also further buttress the fact that large firms who are usually well experienced and have handled numerous projects for different client types have higher CFF process capabilities (Abdullahi, 2014).

\section{Organisational Characteristics}

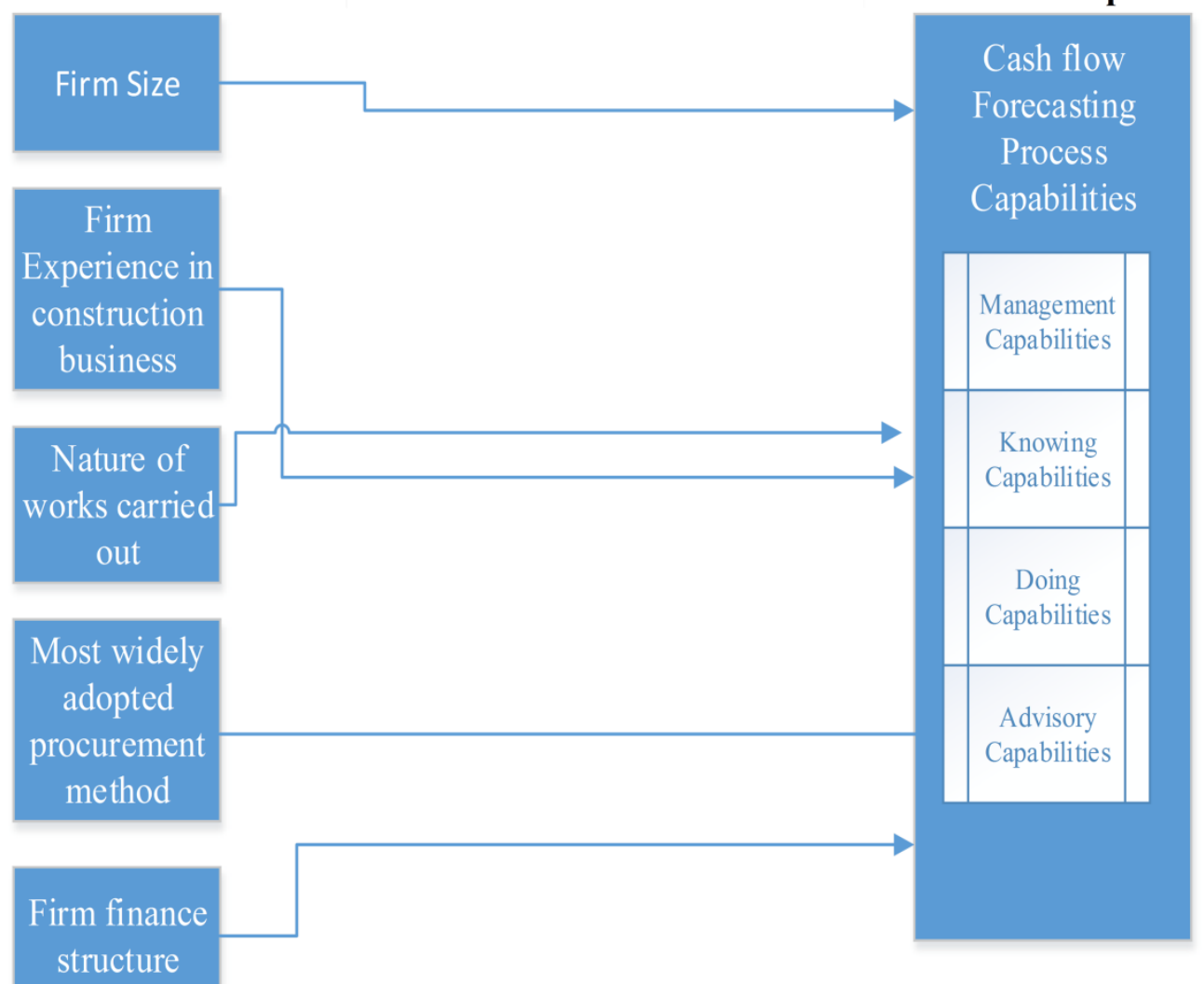

Fig. 2. Relationship mapping between organisational characteristics and CFF process capabilities

Table 7. Results of hierarchical regression models predicting firm's CFF process capabilities

\begin{tabular}{|c|c|c|c|c|c|c|c|c|}
\hline \multirow[b]{2}{*}{ Independent Variables } & \multicolumn{4}{|c|}{ Model 1} & \multicolumn{4}{|c|}{ Model 2} \\
\hline & Coefficient & $\begin{array}{l}\text { Std. } \\
\text { Error }\end{array}$ & Tolerance & VIF & Coefficient & $\begin{array}{l}\text { Std. } \\
\text { Error }\end{array}$ & Tolerance & VIF \\
\hline (Constant) & 0.71 & 0.16 & - & - & 0.72 & 0.24 & - & - \\
\hline Firm Size & 0.65 & 0.05 & 1.00 & 1.00 & 0.69 & 0.06 & 0.80 & 1.26 \\
\hline Nature of Works done & - & - & - & - & -0.06 & 0.07 & 0.84 & 1.19 \\
\hline Firm's Experience & - & - & - & - & -0.09 & 0.04 & 0.91 & 1.10 \\
\hline $\begin{array}{l}\text { Firm's most widely } \\
\text { adopted procurement }\end{array}$ & - & - & - & - & 0.05 & 0.04 & 0.86 & 1.17 \\
\hline Organisational Structure & - & - & - & - & 0.05 & 0.05 & 0.88 & 1.14 \\
\hline R Square & \multicolumn{2}{|c|}{0.628} & \multicolumn{6}{|c|}{0.66} \\
\hline F-Value & \multicolumn{2}{|c|}{141.56} & \multicolumn{6}{|c|}{31.12} \\
\hline$\Delta \mathrm{R}$ & \multicolumn{2}{|c|}{0.628} & \multicolumn{6}{|c|}{0.03} \\
\hline$\Delta \mathrm{F}-$ Value & \multicolumn{2}{|c|}{-} & \multicolumn{6}{|c|}{110.44} \\
\hline F-Value (ANOVA) & \multicolumn{2}{|c|}{$\mathrm{F}(1,84)=141.561$} & \multicolumn{6}{|c|}{$F(5,80)=31.12$} \\
\hline Sig. (ANOVA) & \multicolumn{2}{|c|}{0.00} & \multicolumn{6}{|c|}{0.00} \\
\hline
\end{tabular}




\section{Conclusion and Further Research}

The aim of this study was to empirically examine how contractors' organisational characteristics are associated with their CFF process capabilities. This is solely with the view of identifying the potential features of construction firms that define their capabilities in terms of prudent management of cash flows. This aim was achieved through some specific objectives. The first objective was to identify key best practices (KBPs) in cash flow forecasting and was achieved through the comprehensive review of past literature with information drawn from various sources including academic and industry publications. Information collected was then critically analysed to establish the KBPs used in the study. A long list of forty seven (47) best practices recommended by practitioners and professionals in the construction industry was elicited. The practice guide outlined best practices based on the three major components of the RICS assessment of professional competence (knowing, Doing, and advising) which directly describes the process of CFF. In addition five (5) other management related issues were further identified from literature. These key best practices formed the basis of the assessment by serving as the criteria used for assessing contractors' capabilities.

The second objective was achieved via selfadministered survey conducted among the different categories of contractors as listed by businesslist.com a directory for registered construction firms in Nigeria. The main object of the survey was to carry out the assessment of the CFF capabilities of contractors in Nigeria based on their level of knowledge and understanding of the CFF process (Knowing); Practical application of basic principles of CFF (Doing); other practical considerations (Advising); and the overall management strategies adopted by the contractors to manage the entire CFF process of their projects. Firstly, the survey results indicated that $\mathrm{CFF}$ in Nigeria construction industry is ineffective and not practiced as recommended in literature. The industry is at a low capability level with high need for improvement. It revealed that large and medium sized firms have higher CFF capabilities, especially when compared with the small firms which have low capabilities in virtually all the key components of CFF process. Secondly, the strong and weak areas of practice by the firms were determined from the assessment results. More specifically, the results revealed a high level of application of the BPs in the areas of Knowing (Knowledge and understanding of CFF principles) and Doing (the practical application of CFF principles), but a very weak Advisory (practical considerations) and management capabilities. Furthermore, the large firms have high capabilities in knowing, doing and controlling, but low/weak in the advisory aspect of the process Medium firms have their strong holds in knowing and doing but need some tremendous improvement in the advisory and management areas. The small firms have a very poor CFF process. The practice in these firms needs improvement in virtually all its components, especially in the management aspect which does not exist and the advisory areas which is also at a very low level. Little effort would improve the knowing and doing areas.

Finally, the association between organisation characteristics and their CFF process capabilities were established using Hierarchical regressions. This study concludes that organisational features such as firm size, firm; level of experience, nature of works executed, and most adopted procurement method, and firms' organisational finance structure are strongly related to the abilities of construction firms to effectively and successfully forecast and plan project cash flows. It is recommended that further studies should be undertaken to investigate the influence of organisational culture as a whole on the CFM capabilities of firms.

\section{References}

Abdulrazaq, M. (2015). Developing Models for Predicting the Impact of Risk Factors on Construction Contractors' Cash Flow Forecasts in Nigeria. (Doctor of Philosophy), Ahmadu Bello University, Zaria, Nigeria.

Abdulrazaq, M., Ibrahim, Y. M., and Ibrahim, A. D. (2012). Investigating the Practice of Cash flow forecasting by Contractors in Nigeria. Paper presented at the 4th West Africa Built Environment Research (WABER) Conference, Abuja, Nigeria.

Abudayyeh, O. Y. and Rasdorf, W. J. (1993). Prototype integrated cost and schedule control system. Journal of Computing in Civil Engineering, 7(2), 181-198.

Boussabaine, A. H. and Elhag, T. (1999). Applying fuzzy techniques to cash flow analysis. Construction Management and Economics, 17, 745-755.

Boussabaine, A. H. and Kaka, A. P. (1998). A neural networks approach for cost-flow forecasting. Construction Management and Economics, 16(4), 471-479.

Boussabaine, A. H., Thomas, R., and Elhag, M. S. (1999). Modeling cost-flow forecasting for water pipeline projects using neural networks. Engineering, Construction and Architectural Management, 6(3), 213-224.

Bromilow, F. J. and Henderson, J. A. (1977). Procedures for Reckoning the Performance of Building Contracts (2nd Ed.). CSIRO, Highett, Australia: Division of Building Research.

Chen, C. W., Tsai, C. H., Tseng, C. P., Wang, M. H. L., and Chung, P. Y. (2002). A novel fuzzy regression approach on managing target cash balance for construction firms. Paper presented at the 17th IASTED International Conference on Modeling and Simulation, Montreal, Canada.

Chen, H. L., O’Brien, W. J., and Herbsman, Z. J. (2005). Assessing the accuracy of cash flow models: the significance of payment conditions. Journal of Construction Engineering and Management, 131(6), 669-676.

Cheng, M. and Roy, F. V. (2011). Evolutionary Fuzzy Decision Model for Cash Flow Prediction Using Time-Dependent Support Vector Machines International Journal of Project Management, 19, 5665.

Cui, Q., Hastalk, M., and Halpin, D. (2010). System analysis of project cash flow management strategies. 
Construction Management and Economics, 28(1), 361-376.

Evans, R. C. and Kaka, A. P. (1998). Analysis of the accuracy of standard/average value curves using food retail building projects as case studies. Engineering Construction and Architectural Management, 5(1), 56-68.

Harris, F. and McCaffer, R. (2005). Modern Construction Management (5th ed.). London: Blackwell Science.

Hair, J. F., Black, W. C., Babin, B. J., and Anderson, R. E. (2010). Multivariate data analysis, 7th Ed., Prentice Hall, Upper Saddle River, NJ.

Hegazy, T. and Ersahin, T. (2001). Simplified SpreadsheetbSolutions II: Overall Schedule Optimization. Journal of Construction Engineering and Management, 127(6), 469-475.

Hudson, K. W. (1978). DHSS expenditure forecasting method. Chartered Surveyor-Building and Quantity Surveying Quarterly, 5, 42-45.

Kaka, A. P. and Khosrowshahi, F. (1996). Effect of different procurement routes on contractors' cash flows. Engineering, Construction and Architectural Management, 1(2), 133-145.

Odeyinka, H., Kaka, A., and Morledge, R. (2003). An Evaluation of Construction Cash Flow Management Approaches in Contracting Organisations. Paper presented at the 19th Annual ARCOM Conference,, University of Brighton.

Kaka, A. P. (1999). The development of a benchmark model that uses historical data for monitoring the progress of current construction projects Engineering Construction and Architectural Management, 6(3), 256-266.

Kaka, A. P. and Lewis, J. (2003). Development of a Company Level Dynamic Cash Flow Forecasting Model (DYCAFF). Construction Management and Economics, 2(17), 693-705.

Kaka, A. P. and Price, A. D. (1991). Net Cash Flow Models: Are they reliable?. Construction Management and Economics, 9, 291-308.

Kenley, R. and Wilson, O. D. (1986). A construction project cash flow model-an idiographic approach. Construction Management and Economics, 4, 213232.

Khosrowshahi, F. (1991). Simulation of expenditure patterns of construction projects. Construction Management and Economics, 9(2), 113-132.

Khosrowshahi, F. (2000). A Radical Approach to Risk in Project Management. Paper presented at the 16th ARCOM Conference, Glasgow Caledonian University.

Kim, H. and Grobler, F. (2013). Preparing a Construction Cash Flow Analysis Using Building Information Modeling (BIM) Technology. Journal of Construction Engineering and Project Management, 3(1), 1-9.

Kishore, V., Abraham, D., and Sinfield, J. (2011). Portfolio Cash Assessment Using Fuzzy Systems Theory. Construction Engineering and Management, 137(5), 333-343.

Lu, Q., Won, J., and Cheng, J. C. P. (2016). A Financial Decision Making Framework for Construction Projects Based on 5D Building Information Modeling
(BIM). International Journal of Project Management, 34(1), 3-21.

Miskawi, Z. (1989). An S-curve equation for project control. Construction Management and Economics, 7, 115-124.

Navon, R. (1995). Resource-based model for automatic cash-flow forecasting. Construction Management and Economics, 13(6).

Navon, R. (1996). Company-level cash flow management. Journal of Construction Engineering and Management, 122(1), 22-29.

Odeyinka, H. A., Lowe, J., and Kaka, A. P. (2013). Artificial neural network cost flow risk assessment model. Construction Management and Economics, 32(15), 423-439.

O. S. Okunlola and I. I. Johnson (2013). Determining the Performance of Procurement Methods against Selection Criteria using Outranking-Satisfying Methodology. Journal of Engineering, Project, and Production Management, 3(2), 74-84.

Singh, S. and Pua, W. W. (1984). Cash flow trends for high rise building projects. Paper presented at the 4th International Symposium on Organisation and Management of Construction, Organising and Managing Construction, University of Waterloo, Canada.

Skitmore, M. (1992). Parameter prediction for cash flow forecasting models. Construction Management and Economics, 10, 397-413.

Zayed, T. and Liu, Y. (2014). Cash Flow Modeling for Construction Projects. Engineering, Construction and Architectural Management, 221(2), 170-189.

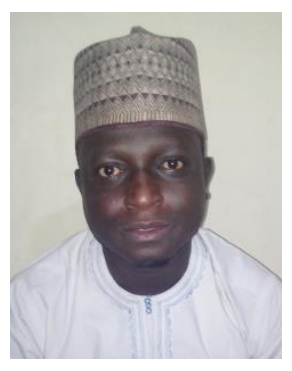

Mr. Abdullahi, Muhammad is a Lecturer and $\mathrm{PhD}$ candidate in the Department of Quantity Surveying, Ahmadu Bello University, and Zaria, Nigeria. He holds BSc (Hons) in Quantity Surveying, MSc in Construction Project Management. His research interest are in Construction Cash Flow Management, Building Information Modeling, and Construction Risk Management. He is a member of the Nigerian Institute of Quantity Surveyors.

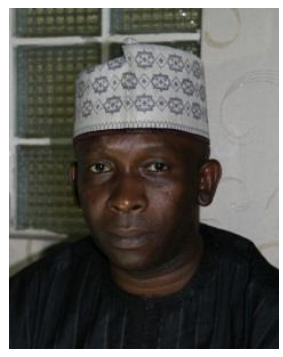

Dr. Ibrahim Yahaya Makarfi is an Associate Professor in the Department of Quantity Surveying, Ahmadu Bello University, and Zaria, Nigeria. He is a member of the Chartered Institute of Building (CIOB), The Association for Project Management (APM) and the Nigerian Institute of Quantity Surveyors (NIQS). His research interests are in Information Technology, Project Monitoring and Control and Strategic Management of Construction Firms. 
44 Abdullahi, M., Ibrahim, Y. M., Ibrahim, A. D., and Ahmadu, H. A.

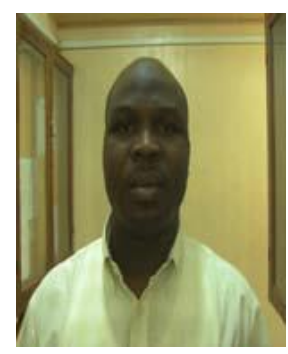

Ibrahim Ahmed Doko is a Professor of Quantity Surveying at Ahmadu Bello University, Zaria, Nigeria. He holds BSc (Hons) in Quantity Surveying, MSc in Construction Engineering \& Management and $\mathrm{PhD}$ in Construction Project Management. Professor Ahmed has research interest in the general areas of Quantity Surveying and Project Management with particular emphasis on Procurement, Cost Modelling, Public-Private Partnerships, Risk Management and Strategic Management of Construction firms. He is a corporate member of the Nigerian Institute of Quantity Surveyors, Association for Project Management (UK), Chartered Institute of Building (UK) and the Society for Construction Industry Arbitrators (Nigeria).

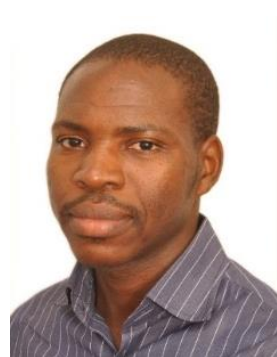

Mr. Ahmadu Hassan Adaviriku is a $\mathrm{PhD}$ student in the Department of Quantity Surveying, Ahmadu Bello University, Zaria, Nigeria and a Lecturer in the department of Quantity Surveying, Federal University, Birnin Kebbi, Nigeria. $\mathrm{He}$ is a probational member of the Nigerian Institute of Quantity Surveyors. His research interest are in construction time performance, risk and uncertainty management and mathematical modelling. 